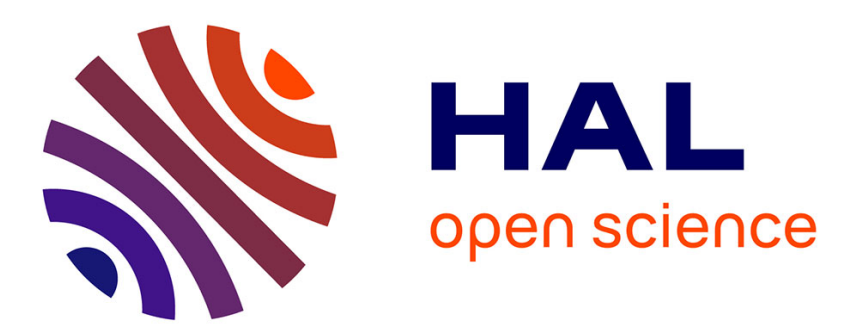

\title{
Dissolution and passivation of aluminide coatings on model and Ni-based superalloy
}

Y. Le Guével, B. Grégoire, M. J. Cristóbal, X. Feaugas, A. Oudriss, F.

Pedraza

\section{- To cite this version:}

Y. Le Guével, B. Grégoire, M. J. Cristóbal, X. Feaugas, A. Oudriss, et al.. Dissolution and passivation of aluminide coatings on model and Ni-based superalloy. Surface and Coatings Technology, 2019, 357, pp.1037-1047. 10.1016/j.surfcoat.2018.10.090 . hal-02467045

\section{HAL Id: hal-02467045 https://hal.science/hal-02467045}

Submitted on 4 Feb 2020

HAL is a multi-disciplinary open access archive for the deposit and dissemination of scientific research documents, whether they are published or not. The documents may come from teaching and research institutions in France or abroad, or from public or private research centers.
L'archive ouverte pluridisciplinaire HAL, est destinée au dépôt et à la diffusion de documents scientifiques de niveau recherche, publiés ou non, émanant des établissements d'enseignement et de recherche français ou étrangers, des laboratoires publics ou privés. 


\title{
DISSOLUTION AND PASSIVATION OF ALUMINIDE COATINGS ON MODEL AND Ni-BASED SUPERALLOY
}

\author{
Y. Le Guével ${ }^{1}$, B. Grégoire ${ }^{1}$, M.J. Cristóbal ${ }^{2}$, X. Feaugas ${ }^{1}$, A. Oudriss ${ }^{1}$, F. Pedraza ${ }^{1 *}$ \\ ${ }^{1}$ Université de La Rochelle. Laboratoire des Sciences de l'Ingénieur pour l'Environnement (LaSIE UMR- \\ 7356). Avenue Michel Crépeau. 17042 La Rochelle, cedex 1. France. \\ ${ }^{2}$ ENCOMAT -Group, University of Vigo, 36310 Vigo, Spain. \\ * corresponding author: fpedraza@univ-Ir.fr
}

\begin{abstract}
Electrolytic dissolution of aluminide coatings on model (pure Ni, Ni2OCr) and René $125 \mathrm{Ni}$-based superalloy was conducted by alternated cathodic and anodic polarizations. The pure nickel aluminide dissolved homogeneously. In contrast, the inhomogeneity of dissolution increased with the incorporation of $\mathrm{Cr}$ in the coating. The coatings were however uniformly dissolved when the cathodic step was eliminated. XPS and TEM demonstrate that the occurrence of a passive layer containing $\mathrm{Cr}$ and Al oxy-hydroxides blocked dissolution.
\end{abstract}

Keywords: aluminide coating; electrolytic dissolution; passivation; XPS; TEM

\section{1.- INTRODUCTION}

Nickel based superalloys are the preferred substrate materials of components operating at high temperature due to their excellent mechanical properties and adequate corrosion resistance [1.]. However, in very harsh conditions additional protective coatings are required among which aluminide coatings are applied in a wide range of applications including aeronautical [2], gas [3] and ultrasupercritical steam turbines [4] as well as in future sodium fast nuclear reactors [5].

Upon service, the aluminide coatings degrade by phase transformation and grow non-protective oxides [6] but can be dissolved (stripped) before recoating. Very few works on stripping are reported in the literature. Based on pitting and oxidizing acids in organic or aqueous media, our group investigated a soft chemical stripping method of NiAl coatings to circumvent the hazards of conventional chemical stripping processes [7]. It appeared that the aqueous solutions were more reactive than the organic ones. Recently, Alam and coll. focused their investigations on the chemical removal of Pt-modified NiAl coatings from a nickel-based superalloy. In their thorough investigations they succeeded in finding an appropriate combination of $\mathrm{HCl}, \mathrm{H}_{3} \mathrm{PO}_{4}$ and $\mathrm{H}_{2} \mathrm{O}$ to remove smoothly the coating [8]. The coating was fully removed, i.e. the additive and the interdiffusion layers but when recoated, the cyclic oxidation behaviour was similar to the new one. The removal of both the additive 
and interdiffusion layers indicate that chemical methods are not selective enough and do not provide in situ monitoring of the progress of dissolution. Therefore, Bouchaud et al. proposed a threeelectrode electrolytic method to dissolve the aluminide coatings from DSR142 Ni-based superalloy using alternated cathodic and anodic polarizations [9]. The cathodic steps were employed to reduce the oxide layers from the coatings and the smut formed upon dissolution while the anodic ones allowed dissolution. However, the galvanostatic polarizations led to some inhomogeneity that Le Guével et al. succeeded to palliate when using a potentiostatic approach to remove the oxide layers

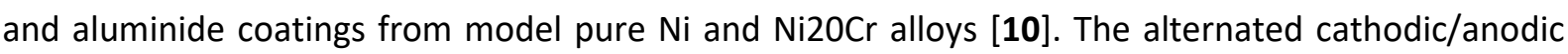
potentiostatic method dissolved progressively the oxides and the aluminide coatings on pure $\mathrm{Ni}$. However, the dissolution was heterogeneous in the aluminized $\mathrm{Ni20} C r$ in spite of the mechanical removal of the oxide scale by grit blasting. It was suggested that dissolution was blocked upon the cathodic polarization steps due to a potential passivation of the coating surface. Very likely, such inhomogeneity was related to the formation of smut at the surface upon dissolution. Some authors have proposed to alternate acidic chemical stripping with basic $(\mathrm{NaOH})$ removal of the smut to allow progress of the dissolution of the coating [11]. Unfortunately, little is known on the dissolution and on the passivation of nickel aluminide compounds. The only study refers to the X-ray Photoelectron Spectroscopy (XPS) characterization of ultra-thin alumina oxide layer (about $5.5 \mathrm{~nm}$ ) grown at $900^{\circ} \mathrm{C}$ from single crystal $\beta-\mathrm{NiAl}$ and its evolution when immersed in $0.5 \mathrm{M} \mathrm{NaCl}$ [12]. Therefore, this work provides experimental evidence on the dissolution and passivation mechanisms on aluminized model

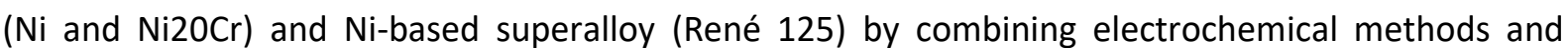
surface analytical techniques.

\section{2.- EXPERIMENTAL}

Substrates of pure $\mathrm{Ni}(99.95 \%), \mathrm{Ni} 20 \mathrm{Cr}(75.7 \mathrm{Ni}, 21.3 \mathrm{Cr}$, 3Si, at\%) and René 125 superalloy $(9.9 \mathrm{Cr}$, 10.3Co, 1.3Mo, 2.6W, 1.3 Ta, 10.8Al, 3.2Ti, 0.5 Hf, at\%) were aluminized by Snecma Vapour Aluminizing Process (SVPA) at $1080^{\circ} \mathrm{C}$ for $6 \mathrm{~h}$ using $80 \mathrm{Cr}-20 \mathrm{Al}$ nuggets and $\mathrm{NH}_{4} \mathrm{~F}$ as activator. The experimental details of the electrochemical tests are widely given in [10]. In essence, the 3-electrode electrochemical cell consists of a working electrode (coated substrate), a counter-electrode (large Pt grid) and a saturated calomel reference electrode (SCE) connected to an ARBIN BT 2000 potentiostat/galvanostat. The electrolytic solution is composed of highly diluted aqueous solution of $5 \mathrm{wt} \% \mathrm{HNO}_{3}, 2 \mathrm{wt} \% \mathrm{HCl}$ and $0.7 \mathrm{wt} \%\left(\mathrm{NH}_{4}\right)_{6} \mathrm{Mo}_{7} \mathrm{O}_{24}, 4 \mathrm{H}_{2} \mathrm{O}(\mathrm{pH} \sim 0)[13]$. The cyclic polarization tests were performed from -1.5 to 2 $\mathrm{V} / \mathrm{SCE}$ and back to $-1 \mathrm{~V}$ at 10 and $20 \mathrm{mV} / \mathrm{s}$ to characterize both the uncoated and the aluminized superalloy and the model substrates. The electrochemical dissolution cycles consisted in repeating alternatively cathodic polarization at $-0.8 \mathrm{~V} / \mathrm{SCE}$ for $3 \mathrm{~min}$ (an initial cathodic polarization lasts 
however for $10 \mathrm{~min}$ to reduce the surface oxides [14]) and anodic polarization at $0.5 \mathrm{~V} / \mathrm{SCE}$ for $6 \mathrm{~min}$ $\left(\mathrm{SCE}=\right.$ saturated calomel electrode). The open circuit potential $\left(E_{\text {ocp }}\right)$ was systematically read for $1 \mathrm{~min}$ between the cathodic and the anodic steps to monitor the surface state of the samples. In the following, one "step" will consist in the combination of (cathodic polarization $+E_{\text {ocp }}+$ anodic polarization). For the continuous anodic dissolution, only the 10-min initial cathodic polarization was applied.

The chemical, structural and microstructural characterizations were performed by scanning electron microscopy/energy dispersive spectrometry (SEM/EDS) in a FEI Quanta 200F environmental microscope with EDAX detector, X-ray diffraction in a Bruker Advance D8 apparatus and Cu ka radiation in the $\theta-2 \theta$ mode and Raman spectroscopy with a Jobin-Yvon LabRam HR8000 spectrometer (He-Ne laser emission of $632.82 \mathrm{~nm}$ ). Optical profilometry was performed with a Wyko-NT1100 in the white light optical interferometry (WLOI) and vertical scanning interferometry (VSI) modes.

Precise surface analysis was performed by X-ray photoelectron spectroscopy (XPS) with a Thermo Scientific K-Alpha ESCA using a monochromatic Al Ka radiation (1486.6 eV) in ultra-high vacuum $\left(6 \times 10^{-9} \mathrm{mbar}\right)$. The photoelectrons were captured at $90^{\circ}$ against the surface of the samples. The spot size selected was $400 \mu \mathrm{m}$ and K-Alpha's charge compensation system was employed during analysis. The survey spectra were recorded with a pass energy of $100 \mathrm{eV}$ and an energy step of $1 \mathrm{eV}$. The high resolution spectra of $\mathrm{C} 1 \mathrm{~s}, \mathrm{O} 1 \mathrm{~s}, \mathrm{Al} 2 \mathrm{p}, \mathrm{Cr} 2 \mathrm{p}, \mathrm{Ni} 2 \mathrm{p}$ and Mo3d were recorded using a pass energy of 20 $\mathrm{eV}$ with an energy step of $0.5 \mathrm{eV}$. The binding energy (BE) scale was calibrated with respect to the $\mathrm{C} 1 \mathrm{~s}$ at $285 \mathrm{eV}$. The atomic concentrations were determined from the XPS peak areas using the Shirley background subtraction routine and the Scofield sensitivity factors.

In addition, the characterization of the crystallographic structure of the passive film was conducted by transmission electron microscopy (TEM) in a JEOL JEM-2011 electron microscope equipped with a LaB $_{6}$ filament at $200 \mathrm{kV}$. The TEM/EDS analyses were performed with an INCA-X sight detector of Oxford Instruments. Thinning of the TEM foils was performed by mechanical polishing to obtain a thickness less than $100 \mu \mathrm{m}$ and subsequent electrolytic thinning in $25 \mathrm{vol} \% \mathrm{HNO}_{3}$ in methanol at $-20^{\circ} \mathrm{C}$ with a double twin-jet electro-polisher at different potentials and times (Tenupol-5, Struers). Note that the investigated surface was protected with a Parafilm ${ }^{\circledR}$ film, and that thinning of the films was performed only from the back side. The TEM results were treated using the Digital Micrograph ${ }^{\circledR}$ software of Gatan.

\section{3.- RESULTS}

\section{1.- Characterization of the coatings}


Figure 1 shows the morphology and the composition (in at\%) of the aluminide coatings on the different substrates.
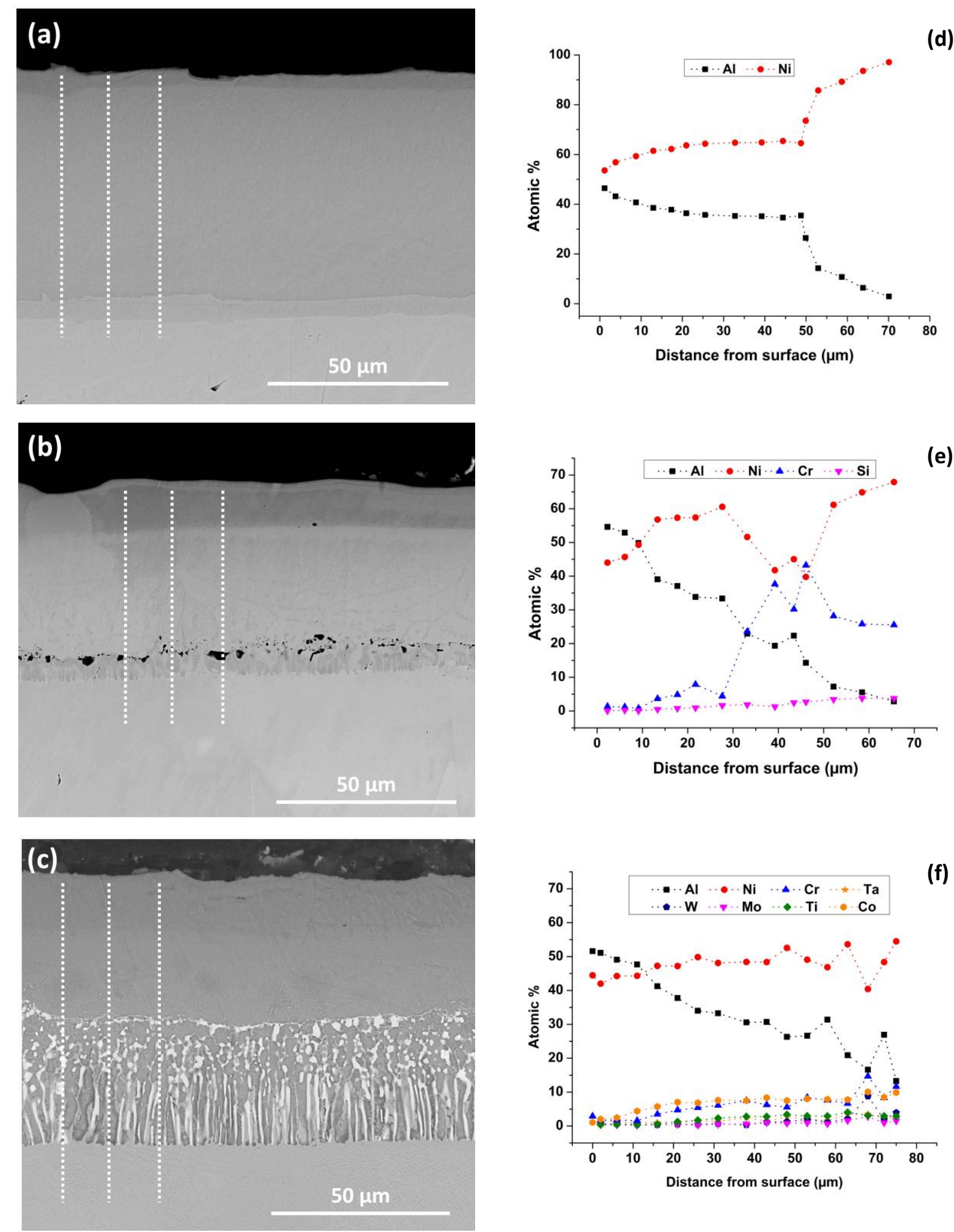

Fig. 1.- SEM cross sections of the aluminide coatings on (a) pure $\mathrm{Ni}$, (b) $\mathrm{Ni20Cr}$ and (c) René 125 superalloy. (d), (e) and (f) are respectively, the EDS composition profiles across such coatings. NB. The dotted lines correspond to the EDS scanning paths. No error bars are plotted for the sake of clarity in the graph. 
Irrespective of the substrate, the aluminide coatings displayed two major layers. The outer layer is often called the diffusion or additive layer and results from major outward diffusion of alloying elements, in particular $\mathrm{Ni}$ at high temperatures [15]. At the very top of this diffusion layer, an additional Al-rich layer between 5 to $10 \mu \mathrm{m}$ is typical of the aluminide coatings grown by SVAP [2]. The second main layer corresponds to the interdiffusion layer and contains a great number of precipitates segregated upon the major countercurrent diffusion of $\mathrm{Al}$ and $\mathrm{Ni}$. The precipitates are composed of $\mathrm{Cr}$ in $\mathrm{Ni20Cr}$ and of refractory elements in René 125 . There are no precipitates in the interdiffusion layer formed in pure $\mathrm{Ni}$. It was also observed that the greater the $\mathrm{Cr}$ content in the alloy, the greater the $\mathrm{Al}$ concentration at the outermost surface of the coating. As such, the Al content decreases from 54.6 to 51.6 and to 46.5 at\% in Ni20Cr, René 125 and Ni, respectively. The Al also decreased steadily in the coating towards the substrate in both alloys but remained constant in the additive layer of pure Ni till the interdiffusion zone was reached. In turn, the Cr content decreased progressively from the substrate to the external coating in model Ni20Cr and René 125 superalloy.

\section{2.- Electrochemical features}

Table 1 gathers the major electrochemical parameters of the aluminide coatings and the uncoated substrates.

Table 1.- Electrochemical data retrieved from cyclic polarization curves (sweep rate: 10 and $20 \mathrm{mV} / \mathrm{s}$ for, respectively, the superalloy and the model materials). ( $J_{\text {diss }}$ is obtained at $0.5 \mathrm{~V} / \mathrm{SCE}$ ). NB: $J_{\text {diss }}$ is the dissolution current, $E_{\text {corr, }}$ the corrosion potential, $E_{\text {rev }}$ is the reversible potential.

\begin{tabular}{lccc|ccc} 
& \multicolumn{3}{c|}{ Uncoated } & \multicolumn{3}{c}{ Aluminized } \\
\cline { 2 - 7 } & $\mathbf{N i}$ & $\mathbf{N i 2 0 C r}$ & $\mathbf{R 1 2 5}$ & $\mathbf{N i}$ & $\mathbf{N i 2 0 C r}$ & $\mathbf{R 1 2 5}$ \\
\hline $\mathrm{E}_{\text {corr }}(\mathrm{mV})$ & $-158 \pm 5$ & $-115 \pm 5$ & $-114 \pm 8$ & $-207 \pm 2$ & $-232 \pm 11$ & $-231 \pm 3$ \\
\hline $\mathrm{E}_{\text {rev }}(\mathrm{mV})$ & $-158 \pm 5$ & $902 \pm 11$ & $944 \pm 15$ & $-207 \pm 2$ & $-232 \pm 11$ & $-259 \pm 2$ \\
\hline$J_{\text {diss }}\left(\mathrm{mA} / \mathrm{cm}^{2}\right)$ & $300 \pm 0$ & $0.62 \pm 0.02$ & $0.70 \pm 0.05$ & $363 \pm 0$ & $395 \pm 14$ & $285 \pm 20$ \\
\hline$\Delta\left(\mathrm{E}_{\text {corr }}-\mathrm{E}_{\text {rev }}\right)(\mathrm{mV})$ & 0 & 1017 & 1058 & 0 & 0 & 28 \\
\hline
\end{tabular}

It can be observed that the uncoated materials increase their $E_{\text {corr }}$ in the presence of $\mathrm{Cr}$. The increase in $\mathrm{E}_{\text {rev }}$ is even much higher and is indicative of the hysteresis of the $\mathrm{Cr}$-containing materials. As a result, the dissolution current is almost negligible at $0.5 \mathrm{~V} / \mathrm{SCE}$. The opposite occurs in pure Ni whose dissolution current density is quite high. The aluminized samples possess lower $E_{\text {corr }}$ and $E_{\text {rev }}$ than the uncoated ones. The values of the $E_{c o r r}$ and the $E_{\text {rev }}$ indicate that the surface of pure nickel and of the aluminized $\mathrm{Ni}, \mathrm{Ni20Cr}$ and René 125 remains active (i.e. dissolution occurs) while the uncoated $\mathrm{Ni20 \textrm {Cr }}$ 
and René 125 may passivate upon the polarization in the potential range studied here. It also appears that the activity of the aluminized surfaces is greater than the one of uncoated $\mathrm{Ni}$. In addition, the electrochemical parameters indicate that the surface activity differ from one aluminide coating to another. The aluminized superalloy seems to dissolve less than the aluminized $\mathrm{Ni20Cr}$, which in turn is equivalent to that of the aluminized $\mathrm{Ni}$.

\section{3.- Electrochemical dissolution with alternated cathodic and anodic polarization}

Figure 2 shows the evolution of the current density with time when increasing the number of dissolution steps. In all cases, the current density drops markedly for the first few seconds of each step. Thereafter, the current density stabilizes at different values. With the increase of the number of steps, the current density values decrease. However, the differences between the substrates are very significant. In aluminized $\mathrm{Ni}$ (Fig. 2a), a progressive decrease of the current density occurs with the number of steps. After 5 or 6 steps, steady values of about $0.22 \mathrm{~A} \mathrm{~cm}^{-2}$ are achieved, which implies that the surface remains active. In the aluminized Ni20Cr (Fig. 2b) and René 125 (Fig. 2C), the current density drops significantly between step 1 and the following ones till passive current densities are achieved.

The Al content against coating thickness is plotted simultaneously with the evolution of the current density and with time in Fig. 3. The current density drops with decreasing the Al content in particular in the aluminized superalloy (Fig. $3 \mathrm{c}$ ). In pure $\mathrm{Ni}$, the dissolution current decreases although the $\mathrm{Al}$

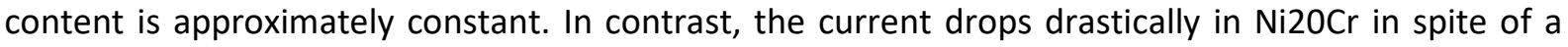
progressive decrease of Al. Nevertheless, the major current drop in all three aluminized substrates occurs in the outermost coating zone, where the Al content is the highest. It thus derives that the greater the Al content, the greater the dissolution but this does not seem to be the only reason for. Indeed, the dissolution is homogeneous only in the aluminized pure $\mathrm{Ni}$.

The progressive removal results in an etched surface where the grains of the Ni substrate are clearly observed (Fig. 4a). In the Cr-containing aluminide coatings, the dissolution is very heterogeneous in particular in Ni20Cr (Fig. 4b) and somewhat less in the aluminized René 125 (Fig. 5). Here, the surface displays elongated features probably related to the $\mathrm{H}_{2}(\mathrm{~g})$ flow upon the extensive bubbling generated during the cathodic steps. Therefore, one can presume that in the $\mathrm{Cr}$-containing coatings the surfaces blocked access to the stripping solution. Additional tests were thus carried out by removing the intermediate cathodic steps and by applying the anodic current in a continuous manner. 


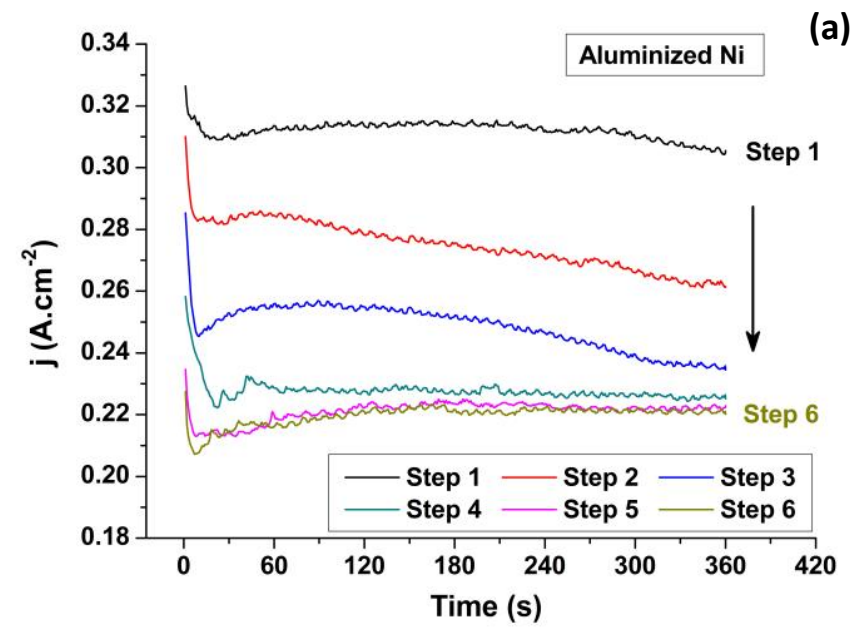

(b)
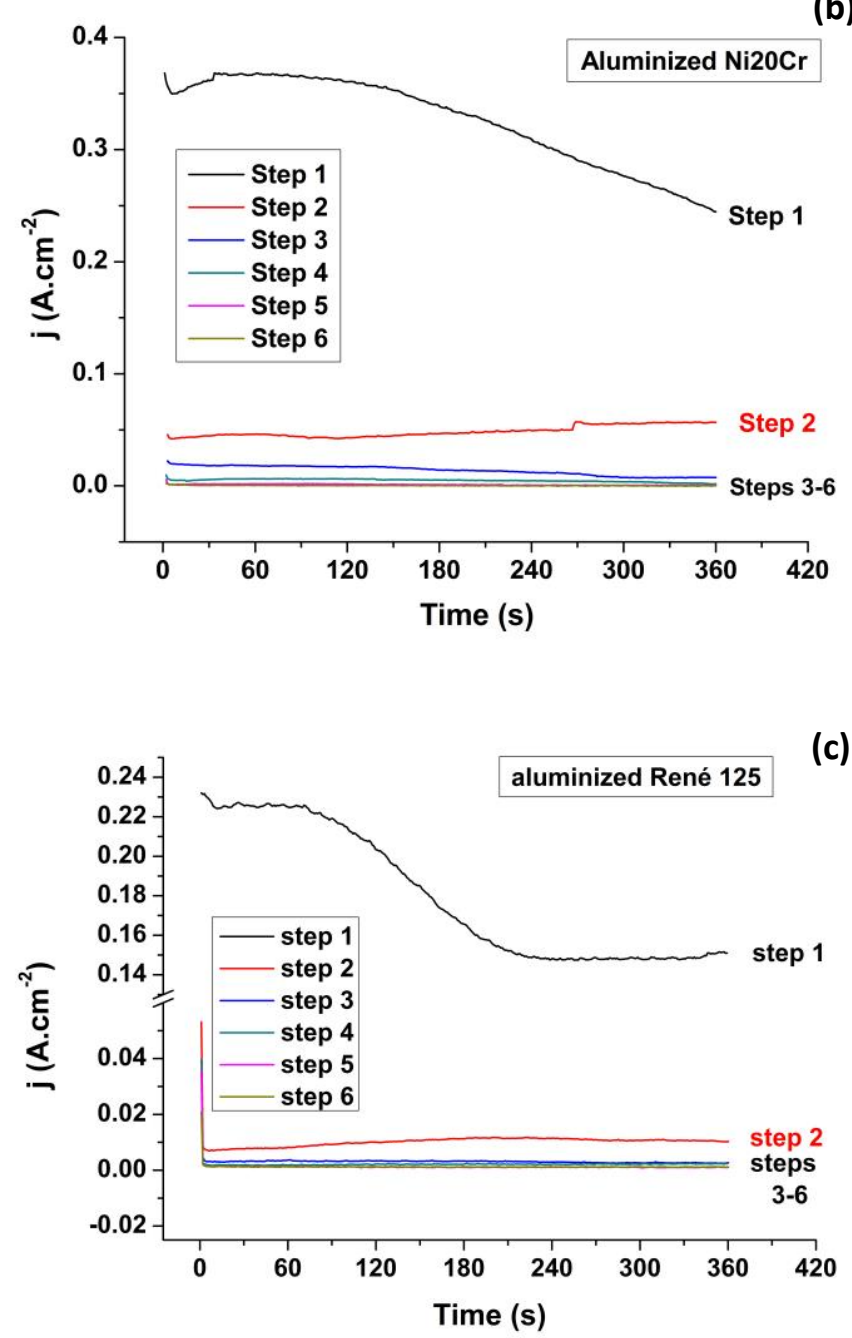

Fig. 2.- Evolution of the current with time of the aluminized (a) pure $\mathrm{Ni}$, (b) $\mathrm{Ni20Cr}$ and (c) René 125 superalloy when increasing the number of dissolution steps. 

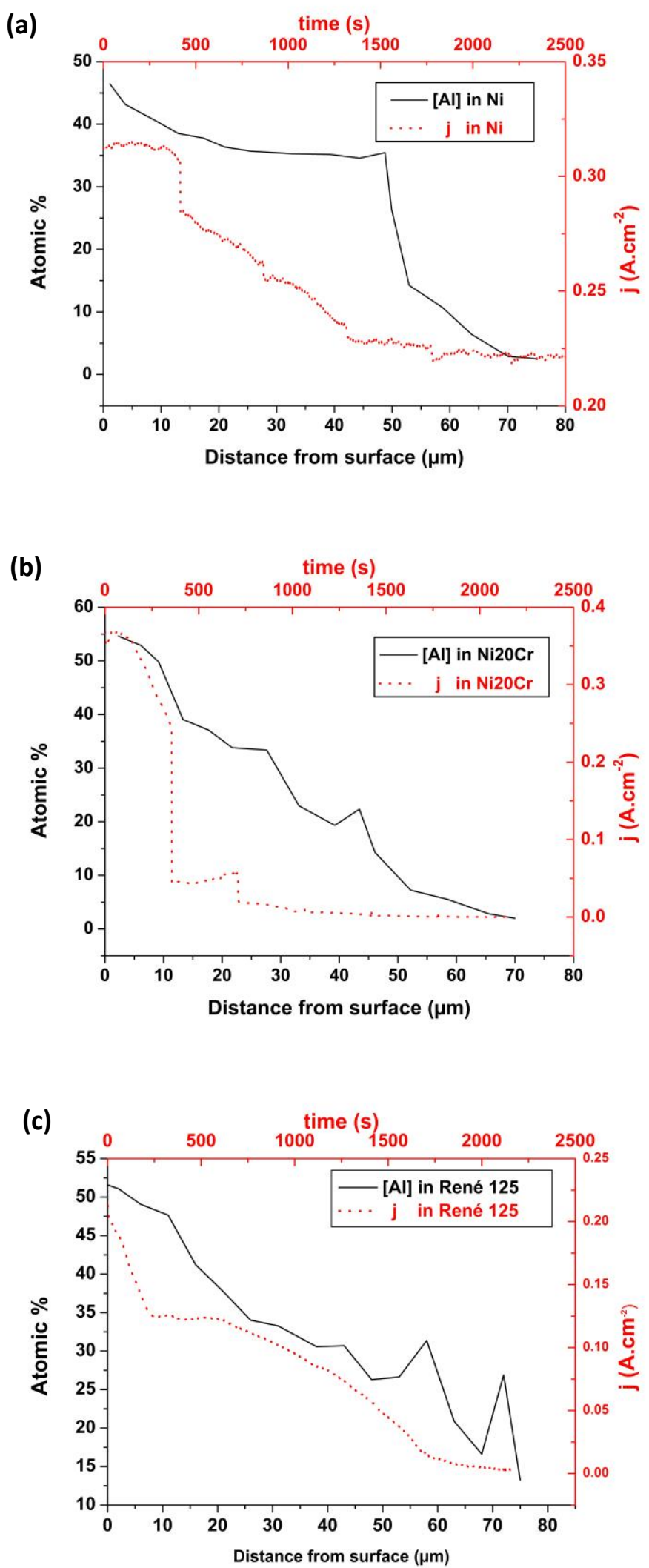

Fig. 3.- Comparative of the Al content in the coatings with evolution of the current with dissolution time. (a) pure Ni, (b) Ni20Cr and (c) René 125 superalloy. 

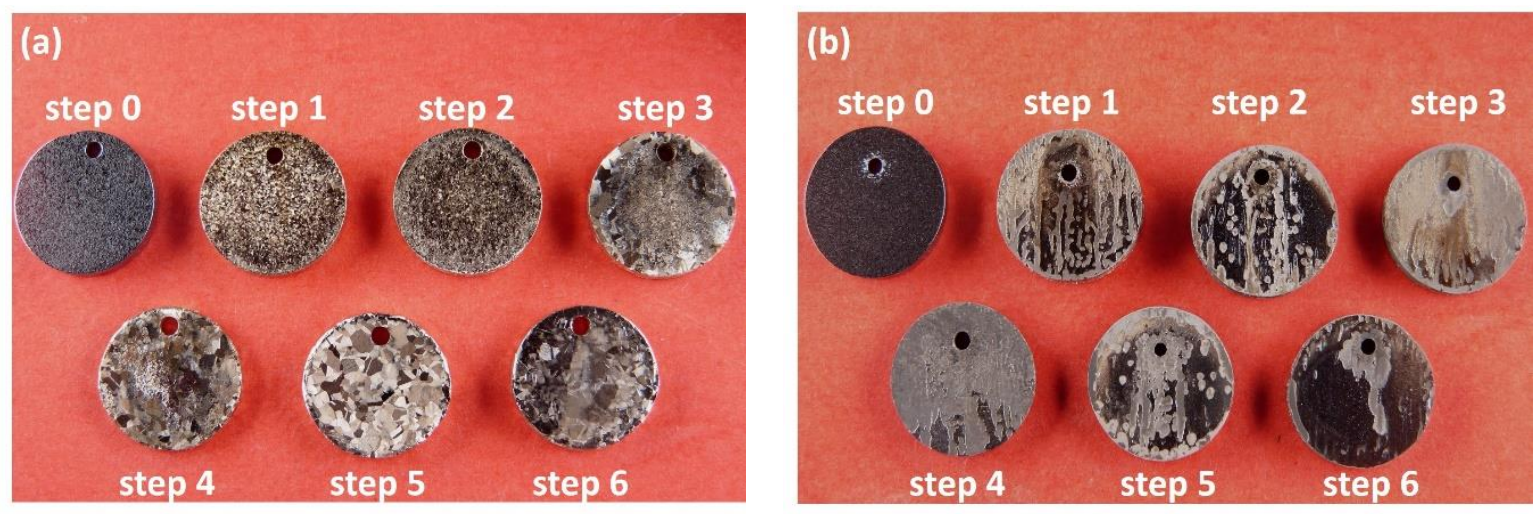

Fig. 4.- Macrographs of the surfaces of aluminized (a) Ni and (b) Ni20 $\mathrm{Cr}$ with increasing the number of stripping steps, i.e. alternated cathodic and anodic polarizations.

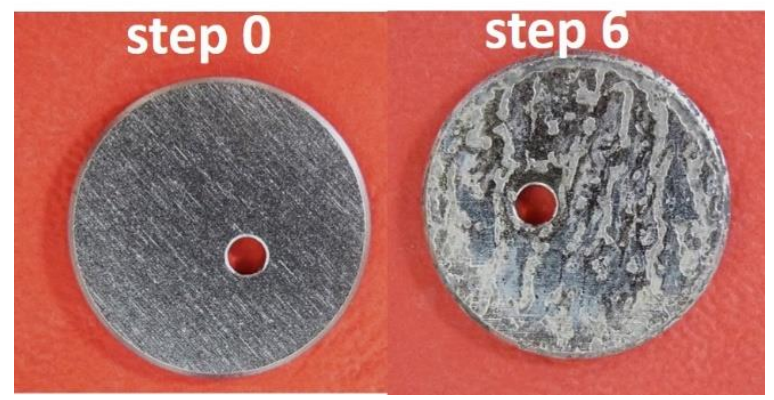

Fig. 5.- Macrographs of the surfaces of aluminized René 125 before and after 6 steps (alternated cathodic and anodic polarizations).

\section{4.- Electrochemical dissolution without cathodic polarization}

Figure 6 compares the two modes of dissolution, i.e. alternated (cathodic/anodic) vs. continuous anodic polarization. After the application of the initial cathodic polarization for $10 \mathrm{~min}$ to remove the surface oxides [14] and the measurement of the $E_{\text {ocp }}$ for $1 \mathrm{~min}$, the current density drops in a relatively steady manner in all three aluminized substrates using the continuous mode at $0.5 \mathrm{~V} / \mathrm{SCE}$ (Fig. $6 \mathrm{~b}$ ). However, as described above, the current decreases sharply after the first anodic polarization in the $\mathrm{Cr}$-containing substrates, which is indicative of passivation upon the cathodic polarization. The current density of the aluminized $\mathrm{Ni}$ is very similar regardless of the stripping mode, which suggests that NiAl does not passivate in this medium. Indeed, the evolution of the current density of the model (bulk) $\mathrm{NiAl}$ with dissolution time is constant, i.e. NiAl dissolves evenly. In turn, in the cathodic mode, the surface activity is lowered with the change in composition of the coatings. These observations strongly suggest that dissolution is enhanced with a greater Al content and that the incorporation of alloying elements $(\mathrm{Cr})$ in the coating lowers the electrochemical activity. Indeed, the comparison of the surfaces with and without cathodic polarization after the first dissolution step displays major differences. 

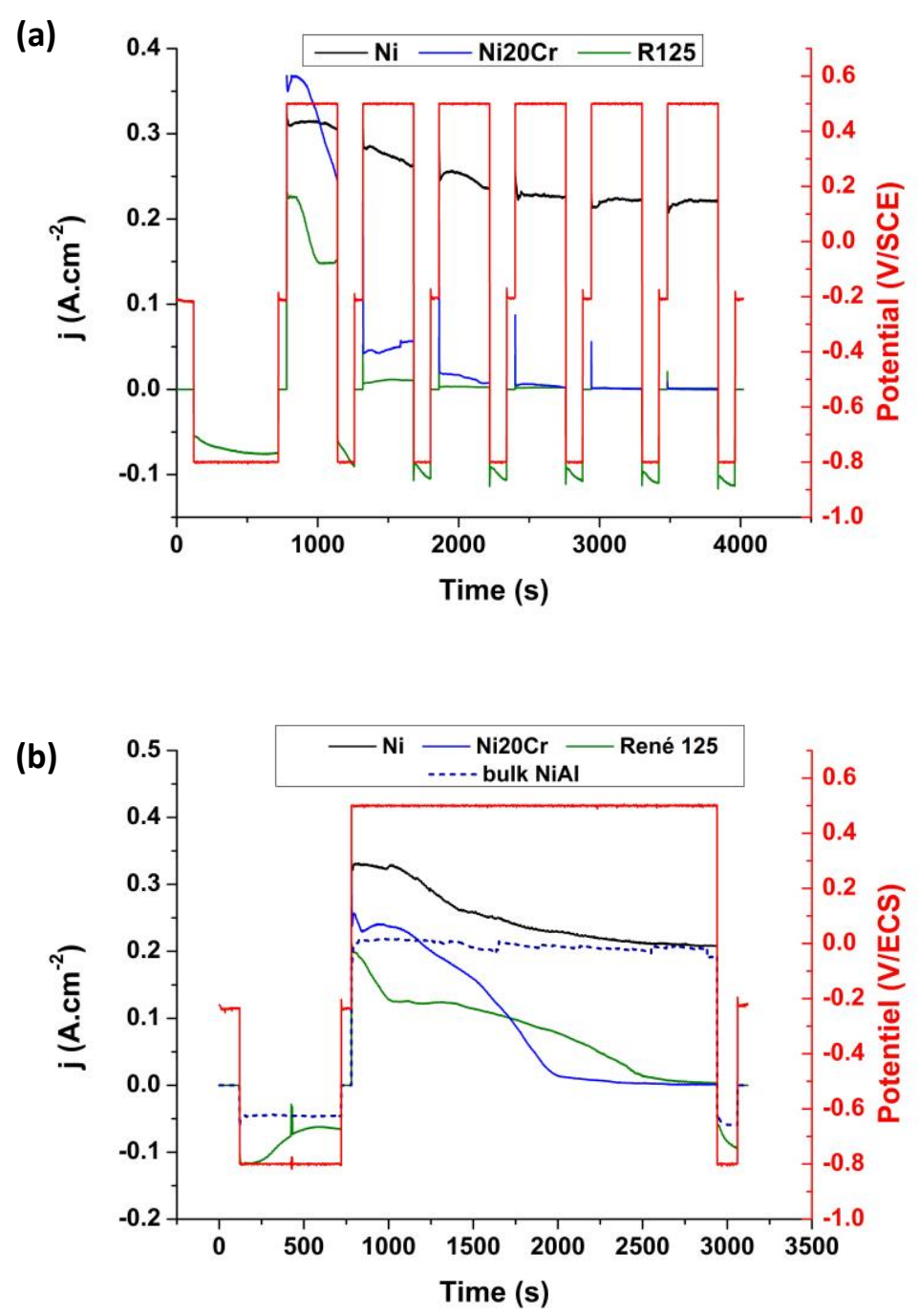

Fig. 6.- Comparative evolution of the current with time of the aluminide coatings on pure $\mathrm{Ni}, \mathrm{Ni2OCr}$ and René 125 superalloy. (a) Alternated cathodic and anodic polarizations (the small jumps are related to the measurement of the $E_{\text {ocp }}$ ). (b) Continuous anodic dissolution (the anodic time is equivalent to the alternating procedure). The behaviour of bulk NiAl is also plotted in (b) for comparative purposes.

The SEM images of Fig. 7 show that the surface of the aluminized René 125 superalloy looks less contrasted after the cathodic polarization (Fig. 7b) than after the dissolution step (Fig. 7a). Also, some of the grains appear preferentially etched during the anodic step and some pits may initiate. Such etched surface is covered with a veil after the cathodic step. The EDS analyses did not highlight any difference of composition between the anodically and cathodically polarized surfaces. Also, we could not observe such veil in the SEM cross-section. In addition, the X-ray patterns in the symmetric mode displayed also the major reflection of the (110) planes of NiAl in all cases. Therefore, these analyses are not shown here. In contrast, some interesting differences are found in the Raman spectra of Fig. 
8. After the cathodic polarization, the peaks are far better defined than after the anodic one. Also, the doublet between $1350-1575 \mathrm{~cm}^{-1}$ often associated with $\alpha-\mathrm{Al}_{2} \mathrm{O}_{3}[\mathbf{1 6 , 1 7 ]}$ does not exist in the anodic domain. The remaining peaks can be related to $\mathrm{CrOOH}$ [18], $\mathrm{Cr}_{2} \mathrm{O}_{3}$ [19] and different classes of aluminium hydroxides and of $\alpha-\mathrm{Al}_{2} \mathrm{O}_{3}$ [17] as summarized in Table 2. It appears that the aluminium derivatives are more abundant in the anodic domain while the chromium compounds are more frequent in the cathodic domain. The latter would slow down the dissolution but there is no clear identification of such compounds.
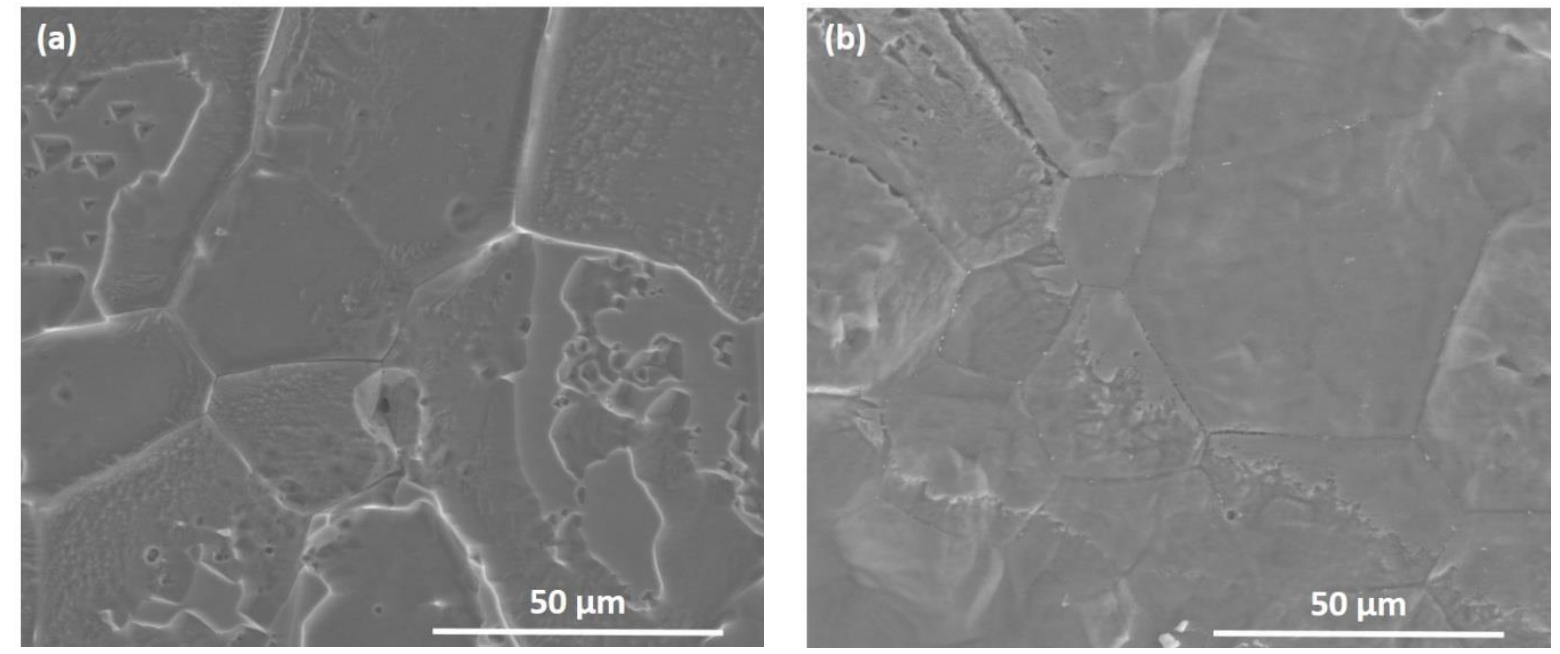

Fig. 7.- SEM surface morphology of the aluminized René 125 superalloy after the (a) anodic and (b) cathodic polarizations. Note the differently contrasted surfaces.

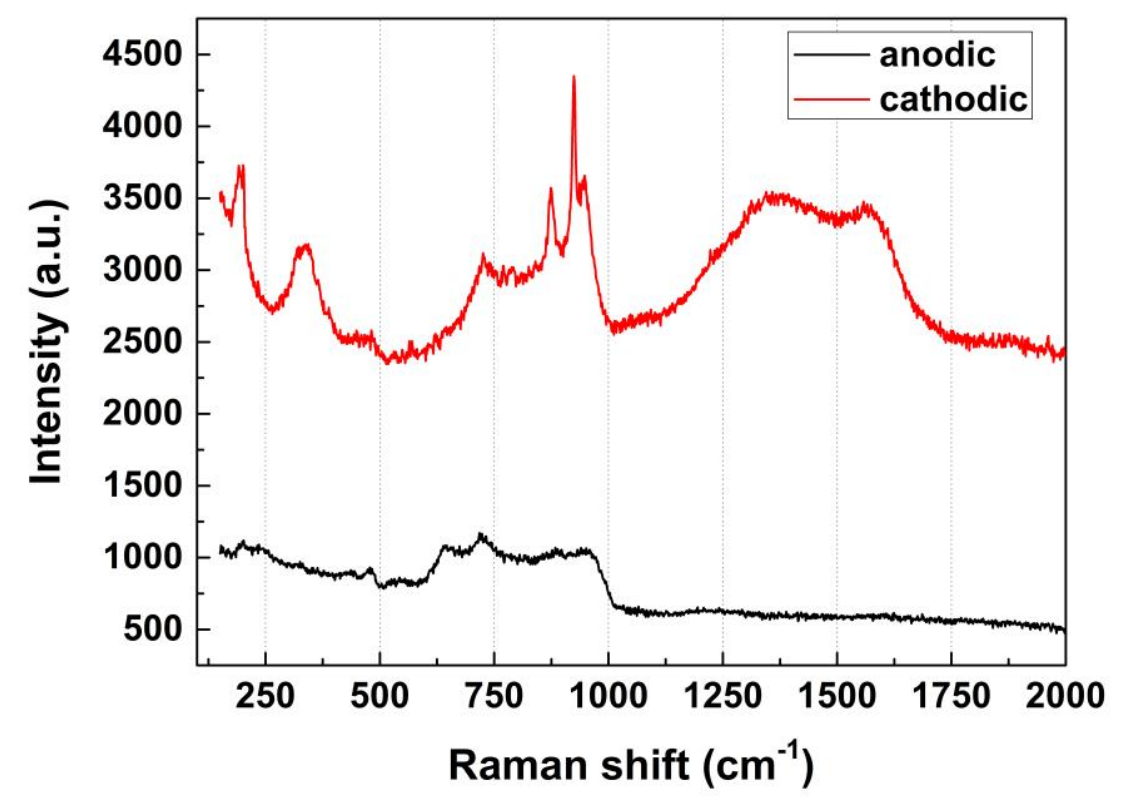

Fig. 8.- Raman spectra of the aluminized René 125 superalloy after the (a) anodic and (b) cathodic polarizations. 
Table 2.- Raman shift $\left(\mathrm{cm}^{-1}\right)$ after the cathodic and the anodic polarizations and comparison with data from the literature [17-19].

\begin{tabular}{ll|ll}
\hline CATHODIC & Proposed compound & ANODIC & Proposed compound \\
\hline 194 & $\mathrm{CrOOH}$ & 202 & $\mathrm{CrOOH}, \mathrm{Al}(\mathrm{OH})_{3}$ nordstrandite \\
$322-337$ & $\mathrm{CrOOH}, \mathrm{Cr}_{2} \mathrm{O}_{3}$ & 579 & $\mathrm{CrOOH}, \mathrm{AlOOH}$ (diaspore) \\
471 & $\mathrm{CrOOH}, \mathrm{AlOOH}$ (diaspore) & 642 & $\mathrm{Cr}_{2} \mathrm{O}_{3}, \mathrm{AlOOH}$ (boehmite) \\
& & 639 & $\mathrm{Al}(\mathrm{OH})_{3}$ nordstrandite \\
726 & $\mathrm{CrOOH}, \alpha-\mathrm{Al}_{2} \mathrm{O}_{3}$ & & $\mathrm{AlOOH}\left(\right.$ boehmite), $\alpha-\mathrm{Al}_{2} \mathrm{O}_{3}$ \\
792 & & 890 & \\
875 & $\mathrm{CrOOH}$ & $\mathrm{CrOOH}, \mathrm{Al}(\mathrm{OH})_{3}$ nordstrandite \\
924 & & 960 & $\alpha-\mathrm{Al}_{2} \mathrm{O}_{3}$ \\
960 & $\alpha-\mathrm{Al}_{2} \mathrm{O}_{3}$ & & \\
\hline
\end{tabular}

\section{5.- Surface analyses after 2 dissolution steps.}

Here, the hypothesis is that the surface dissolution of the aluminide coatings is slowed down because of the formation of passive film containing $\mathrm{Cr}$ derivatives. Therefore, XPS and TEM analyses were performed on the aluminized model $\mathrm{Ni20} C r$ samples that had been polarized cathodically $(-0.8 \mathrm{~V} / \mathrm{SCE}$ for $10 \mathrm{~min}$ ) once to reduce the surface oxides [14], and twice the alternated anodic (0.5 V/SCE for 6 $\mathrm{min}$ ) and cathodic (-0.8 V/SCE for $3 \mathrm{~min}$ ) i.e., where the current density dropped drastically (Fig. $2 \mathrm{~b}$, "step 2") and the surface was inhomogeneously stripped (Fig. 5b, "step 2"). This represents about $10 \mu \mathrm{m}$ below the coating/gas interface. Two clearly distinctive areas appeared with very low differences in surface roughness between them. The "stripped" areas had $R_{a}$ values of about $0.83 \mu \mathrm{m}$ whereas the "non stripped" ones had $R_{a}$ values of $0.91 \mu \mathrm{m}$. However, the maximum heights (depths) against the zero level surface are of 40 and $26 \mu \mathrm{m}$, respectively. This confirms that some grains dissolved more than the others. These areas were sufficiently large to focus the beam for the XPS analyses (Fig. 9). The spot size of the X-rays is $400 \mu \mathrm{m}$, as was indicated in the experimental procedure. 


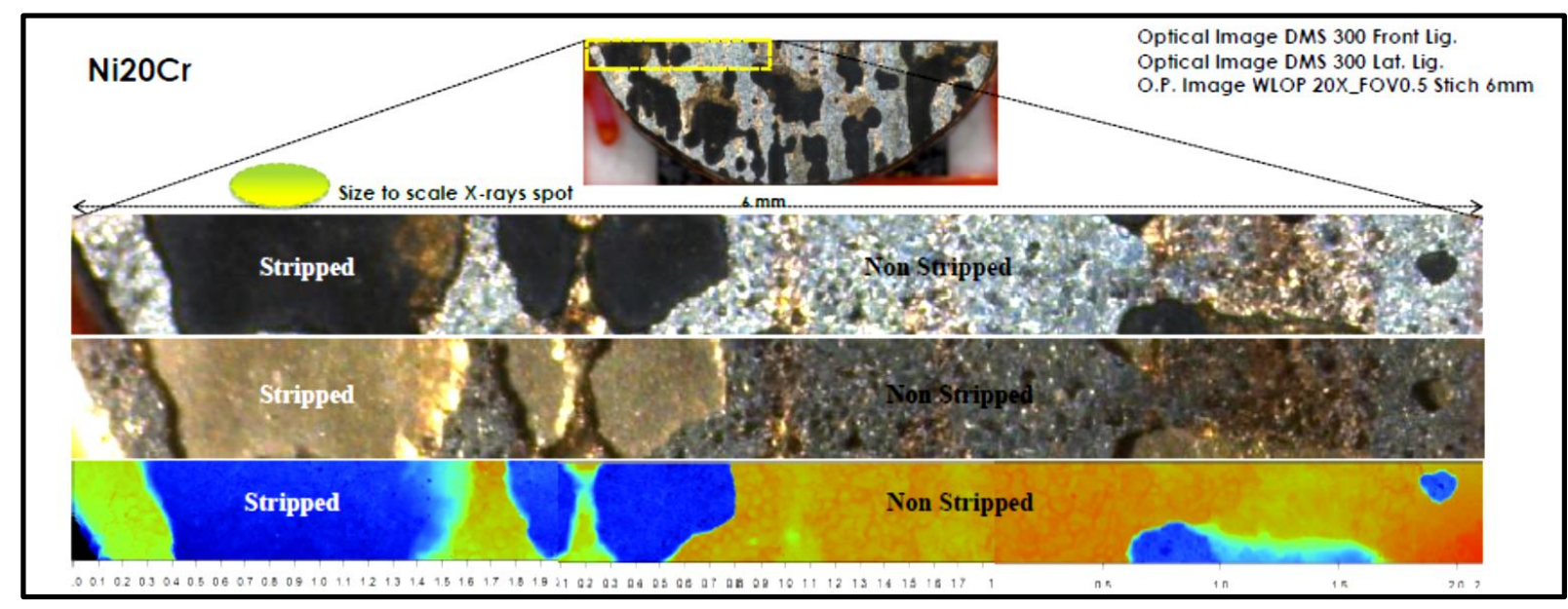

Fig. 9.- Appearance of the aluminized $\mathrm{Ni20Cr}$ after 2 steps of alternated dissolution showing different contrasted modes of the surface. Note that the size of the X-ray spot is sufficiently small to differentiate the "stripped" against the "non stripped" areas.

Without cleaning the surface by $\mathrm{Ar}^{+}$sputtering, Al was the major metal peak observed in the X-ray photoelectron spectra. The peak of $\mathrm{Cr}$ was barely observed. After a very light sputtering to remove surface contaminants, the peaks of $\mathrm{Cr}$ could be unambiguously identified. This suggests that the major external oxide is made of Al (about 3 to $5 \mathrm{~nm}$ deep in the surface). However, the high-resolution XPS spectra of the main elements were recorded without any sputtering of the surface to avoid potential reduction of the species.

Table 3 summarizes the binding energies of the main XPS peaks identified on the surface of the "stripped" and "non-stripped" areas. The value for the C 1s peak can be ascribed to hydrocarbon contamination $[\mathbf{1 2}, \mathbf{2 0}]$. The oxygen peaks can be associated with anionic oxygen in pure oxides and in hydroxides [21-23]. In addition to the oxygen associated with metal oxides and hydroxides, the 01s binding energy of many compounds and species like water and organic contamination falls within a very narrow range. Therefore, the O1s peaks tend to be broad, with multiple overlapping components. In this study, because of the significant organic contamination at the surface of the samples, the deconvolution of the $\mathrm{O}$ 1s emission, the contribution of the oxides and hydroxides species as well as the organic hydrocarbon contamination species was considered.

The binding energies of the $\mathrm{Al} 2 \mathrm{p}, \mathrm{Cr} 2 \mathrm{p}, \mathrm{Ni} 2 \mathrm{p}$ and Mo3d peaks in the stripped areas are generally lower than those of the non-stripped ones. Also, the quantification of the different species displayed in Table 4 indicates that the oxidized elements are more abundant in the non-stripped areas than in the stripped ones, where the metals are majorly in their ground chemical state. 
Table 3.- Main XPS binding energies identified on the surface of the "stripped" and "non-stripped" areas of as-received samples (before sputtering). The experimental values are compared with data from the literature.

\begin{tabular}{|c|c|c|c|}
\hline \multirow[b]{2}{*}{ Element } & \multicolumn{2}{|c|}{ Experimental binding energies (eV) } & \multirow{2}{*}{ Literature values (eV) } \\
\hline & Stripped & Non-stripped & \\
\hline C 1s (C-C, C-H) & 285.0 & 285.0 & 284.6 : Cgraphite, or hydrocarbon [20] \\
\hline $\mathrm{C} 1 \mathrm{~s}(\mathrm{C}-\mathrm{O}-\mathrm{C}, \mathrm{C}-\mathrm{OH})$ & ------ & 286.6 & $284.8:(\mathrm{C}-\mathrm{C}, \mathrm{C}-\mathrm{H})[\mathbf{2 1}]$ \\
\hline $\mathrm{C} 1 \mathrm{~s}(\mathrm{C}=\mathrm{O})$ & 287.5 & ------ & 285.0: $\left(-\mathrm{CH}_{2}-\mathrm{CH}_{2}-\right)[12]$ \\
\hline C 1s $(O-C=0)$ & ------ & 288.9 & $286.3:(\mathrm{C}-\mathrm{O}-\mathrm{C}, \mathrm{C}-\mathrm{OH})[21]$ \\
\hline \multirow[t]{2}{*}{ C 1s (Carbide) } & 283.4 & -------- & $287.6-287.8: C=0[21]$ \\
\hline & & & $288.4-289.1:(\mathrm{O}-\mathrm{C}=\mathrm{O})[\mathbf{2 1}]$ \\
\hline \multirow[t]{5}{*}{ O 1s } & $530.71\left(\mathrm{O}-\mathrm{Cr}^{3+}\right)$ & $532.0\left(\mathrm{O}-\mathrm{Cr}^{3+}, \mathrm{O}-\mathrm{Al}^{3+}\right)$ & 529.8-530.8 : pure $\mathrm{Cr}_{2} \mathrm{O}_{3}[22]$ \\
\hline & $531.81\left(\mathrm{O}-\mathrm{Al}^{3+}\right)$ & 532.7 (C-O-C) & 529.7-533.0 : native $\mathrm{Cr}$ oxide [23] \\
\hline & $532.67(C=0)$ & $533.5\left(\mathrm{OH}^{-}\right)$ & $531.6: \mathrm{OH}-$ ions $[24]$ \\
\hline & $533.43\left(\mathrm{OH}^{-}\right)$ & $534.5(\mathrm{O}-\mathrm{C}=\mathrm{O})$ & $532.8: \mathrm{Al}_{2} \mathrm{O}_{3}$ \\
\hline & & & 530.3 : AlOOH (boehmite) [12] \\
\hline \multirow[t]{4}{*}{ Al $2 p$} & $72.7\left(\mathrm{Al} \mathrm{I}^{0}\right)$ & $74.3\left(\mathrm{~A} \mathrm{I}^{0}\right)$ & $72.9: \mathrm{Al}^{0} \quad[22]$ \\
\hline & $74.5\left(\mathrm{Al}^{3+}\right)$ & $76.6\left(\mathrm{Al}^{3+}\right)$ & doublet 73.1 and $73.5: \mathrm{Al}^{0}[\mathbf{1 2}]$ \\
\hline & & & $75.8: \mathrm{Al}^{3+}[12]$ \\
\hline & & & $75.5: \mathrm{Al}^{3+}[25]$ \\
\hline \multirow[t]{8}{*}{$\operatorname{Cr} 2 p_{3 / 2}$} & $574.6 \mathrm{Cr}^{0}$ & $576.6 \mathrm{Cr}^{0}$ & $574.2: \mathrm{Cr}^{0}[21]$ \\
\hline & $577.2\left(\mathrm{Cr}^{3+}\right)$ & $579.4\left(\mathrm{Cr}^{3+}\right)$ & $576.8: \mathrm{Cr}^{3+}$ in $\mathrm{Cr}_{2} \mathrm{O}_{3}$ \\
\hline & & & $576.4: \mathrm{Cr}^{3+}$ in $\mathrm{Cr}_{2} \mathrm{O}_{3}[26]$ \\
\hline & & & $577.9: \mathrm{Cr}^{3+}$ in $\mathrm{Cr}(\mathrm{OH})_{3}[27]$ \\
\hline & & & $576.5: \mathrm{Cr}^{3+}$ in passive film [28] \\
\hline & & & 574.4-577.7 : native $\mathrm{Cr}$ oxide at [23] \\
\hline & & & $578.2: \mathrm{Cr}^{3+}$ in $\mathrm{Cr}(\mathrm{OH})_{3}[29]$ \\
\hline & & & 575.9-577.1: $\mathrm{Cr}$ in pure $\mathrm{Cr}_{2} \mathrm{O}_{3}[22]$ \\
\hline \multirow[t]{4}{*}{$\mathrm{Ni} 2 \mathrm{p}_{3 / 2}$} & $853.1\left(\mathrm{Ni}^{0}\right)$ & $854.7\left(\mathrm{Ni}^{0}\right)$ & $852.8: \mathrm{Ni}^{0}[24]$ \\
\hline & & & $854.0: \mathrm{Ni}^{0}[12]$ \\
\hline & & & $856.4: \mathrm{Ni}(\mathrm{OH})_{2}[24]$ \\
\hline & & & $856.8: \mathrm{Ni}^{2+}[12]$ \\
\hline \multirow[t]{4}{*}{ Mo $3 d_{5 / 2}$} & $228.5 \mathrm{Mo}^{0}$ & $230.2 \mathrm{Mo}^{0}$ & $227.8: \mathrm{Mo}^{\circ}$ \\
\hline & $230.2 \mathrm{Mo}^{4+}$ & $231.5 \mathrm{Mo}^{4+}$ & $229.5: \mathrm{Mo}^{4+}$ \\
\hline & & $234.4 \mathrm{Mo}^{6+}$ & $231.3: \mathrm{Mo}^{\mathrm{nt}}$ \\
\hline & & & $232.6: \mathrm{Mo}^{6+}[14]$ \\
\hline
\end{tabular}


Table 4.- Chemical state and content of the main different species in the stripped and in the nonstripped areas of the aluminized Ni20Cr after deconvolution of their respective XPS high resolution spectra before sputtering.

\begin{tabular}{lcc}
\cline { 2 - 3 } & \multicolumn{2}{c}{ Atomic \% } \\
\hline Element (state) & Stripped & Non-stripped \\
\hline Al (0) & $\mathbf{6 4 . 2 4}$ & 22.31 \\
Al (+III) & 35.76 & $\mathbf{7 7 . 6 9}$ \\
\hline Cr (0) & $\mathbf{5 7 . 5 9}$ & 47.10 \\
Cr (+III) & 42.41 & $\mathbf{5 2 . 9 0}$ \\
\hline Mo (0) & $\mathbf{7 4 . 4 3}$ & 31.43 \\
Mo (+IV) & 25.67 & $\mathbf{4 0 . 1 2}$ \\
Mo (+VI) & -- & $\mathbf{2 8 . 4 5}$ \\
\hline
\end{tabular}

After light sputtering of the surface to remove surface contaminants, the content of the main elements retrieved by XPS is in line with the previous observations, i.e. the non-stripped areas appear more oxidized with a greater content of oxygen than the stripped ones (Table 5). Further, the concentration of $\mathrm{Al}, \mathrm{Cr}$ and $\mathrm{Mo}$ is higher than in the stripped areas. In contrast, the stripped areas contain more $\mathrm{Ni}$ than the non-stripped ones. It should be noted that this percentage has been calculated eliminating from the quantification the elements that do not really belong to the sample in a natural way such as nitrogen and carbon.

Table 5.- Content of the main different elements in the stripped and in the non-stripped areas of the aluminized Ni20Cr after very light sputtering.

\begin{tabular}{lc|c}
\cline { 2 - 3 } & \multicolumn{2}{c}{ Atomic \% } \\
\hline Element (state) & Stripped & Non-stripped \\
\hline O & 27.1 & 46.5 \\
$\mathrm{Ni}$ & 44.7 & 8.0 \\
$\mathrm{Al}$ & 22.5 & 27.0 \\
$\mathrm{Cr}$ & 3.2 & 3.7 \\
Mo & 1.6 & 7.0 \\
\hline
\end{tabular}

Additional surface investigations to unveil the structural features of the surface chemical compounds were thus performed by TEM and selected area diffraction patterns like the ones shown in Figure 10, 
which appear to be representative of the non-stripped ones. Fig. 10a shows the bright field image where there is a gradient of thickness from the external layer (brighter) to the substrate (darker). Overall, the layer is about $250 \mathrm{~nm}$. At greater magnifications (Fig. 10b), the distance between each interplanar distance is about $1.90 \mathrm{~nm}$. The three selected area diffraction patterns shown in Figs. 10c, $10 \mathrm{~d}$ and $10 \mathrm{e}$ were taken respectively, at about 25,100 and $150 \mathrm{~nm}$ from the gas/material interface (Fig. 10a). The interplanar distances $d_{\mathrm{hkl}}$ were compared with those of many different probable compounds. It appeared that most of the distances correspond to the orthorhombic $\mathrm{CrOOH}$ (JCPDS no. 01-074-4780) and to AIOOH (JCPDS no. 01-78-4590) in addition to NiAl for the deepest pattern (JCPDS no. 0365-0420) according to table 6.
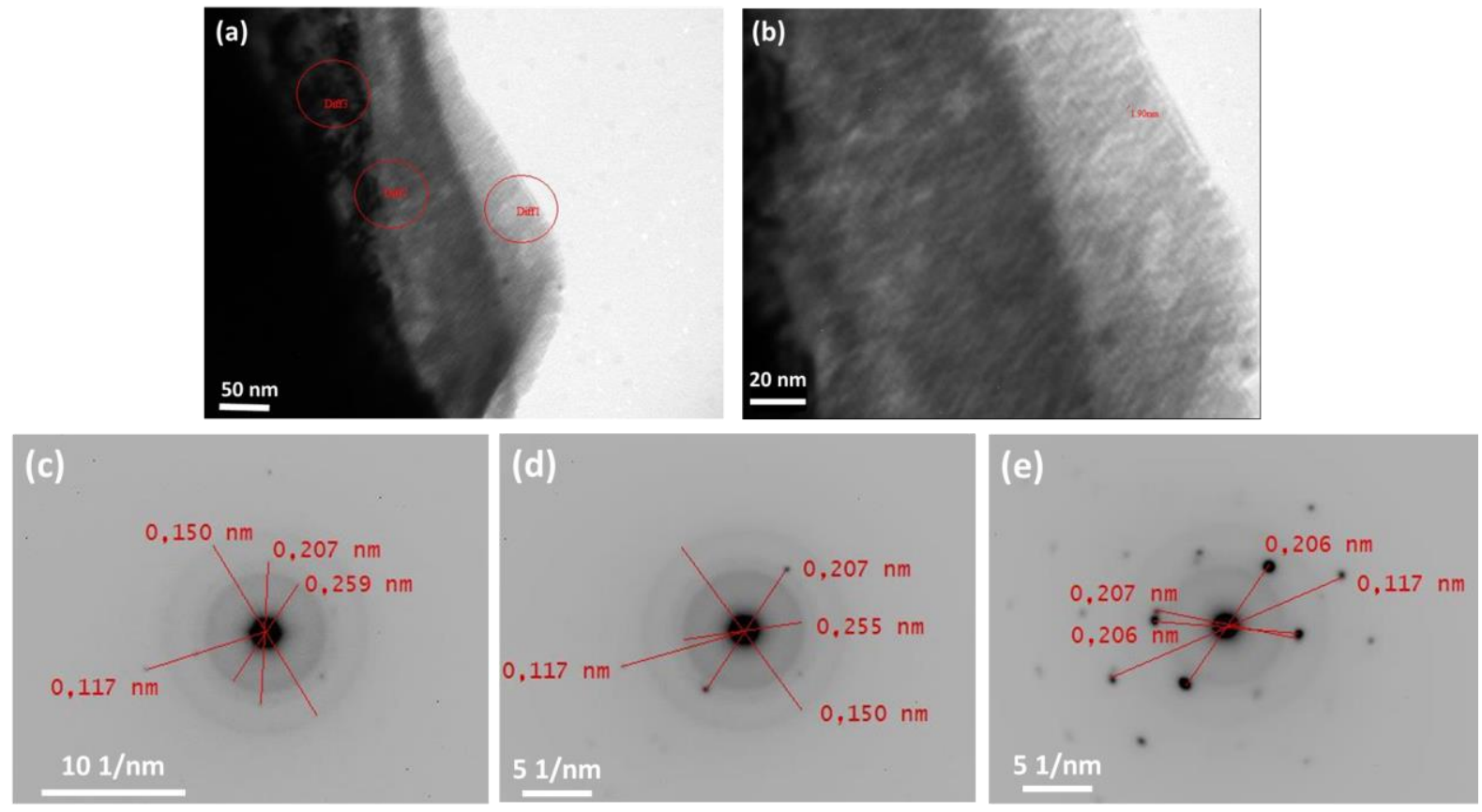

Fig. 10.- TEM bright field images of the passive film of the aluminized Ni20Cr (a). (b) is a greater magnification showing the distance between the crystalline planes. (c), (d) and (e) are the selected area diffraction patterns of the three diffracted areas defined on (a). The distances marked in red correspond to "d", i.e. the interplanar distance. 
Table 6.- Interplanar distances calculated from the selected area diffraction patterns of Fig. 10 and correspondence to the crystalline planes of the identified compounds from ICDD files 01-074-4780 (CrOOH), 01-078-4587 and 01-078-4590 (AlOOH) and 03-065-0420 (NiAl).

\begin{tabular}{|c|c|c|c|c|c|}
\hline \multicolumn{3}{|c|}{ experimental $d_{h k l}(\AA)$} & \multicolumn{3}{|c|}{ standard d $d_{h k l}(\AA)$ and (hkl) } \\
\hline Diff 1 & Diff 2 & Diff 3 & $\mathrm{CrOOH}$ & $\mathrm{AlOOH}$ & NiAl \\
\hline 2.59 & 2.55 & -- & $2.54 ;\{101\}$ & -- & -- \\
\hline \multirow[t]{2}{*}{2.07} & 2.07 & 2.06 & $2.05 ;\{104\}$ & $2.07 ;\{210\}$ & $2.04 ;\{110\}$ \\
\hline & & & & $2.04 ;\{111\}$ & \\
\hline \multirow[t]{3}{*}{1.50} & 1.45 & -- & $1.49 ;\{110\}$ & $1.51 ;\{220\} ;$ & -- \\
\hline & & & $1.48 ;\{009\}$ & $1.48 ;\{310\}$ & \\
\hline & & & $1.42 ;\{113\}$ & & \\
\hline 1.17 & 1.16 & 1.16 & $1.16 ;\{205\}$ & $1.16 ;\{230\}$ & $1.17 ;\{211\}$ \\
\hline
\end{tabular}

\section{4.- DISCUSSION}

\section{1.- Coatings}

All the aluminide coatings exhibited the typical microstructure of outwardly grown diffusion coatings [30]. The aluminide coating in pure Ni displayed a lower content of Al than the ones obtained in the alloys Ni20Cr and René 125 . This is because the aluminizing process at $1080^{\circ}$ for $6 \mathrm{~h}$ is optimized for nickel-based superalloys, for which interdiffusion of $\mathrm{Al}$ and of $\mathrm{Ni}$ is hampered by the alloying elements of the substrate. Therefore, Al diffused into the pure Ni substrate to result in Ni(Al) with lower contents than in stoichiometric $\beta$-NiAl. In Ni20Cr and René 125, the Al content at the surface of the coating is greater than in the aluminide coating formed in pure $\mathrm{Ni}$. This results from the incorporation of $\mathrm{Cr}$ from the substrate to the aluminide that blocks Al inward diffusion [31,32], which in turn provokes the drop of the Al content in the interdiffusion layer of the coating. The $\mathrm{Cr}$ barrier effect is clearly demonstrated when comparing the composition profiles of Figs. 1d, 1e and 1f. However, the amount of $\mathrm{Cr}$ at the outermost surface of the coating is somewhat greater in René 125 (2.9 at\%) than in Ni20 Cr (1.3 at\%) because the alloying elements of the substrate increase the solubility of $\mathrm{Cr}$ in the aluminide coating. The tiny precipitation of $\alpha-\mathrm{Cr}$ at the grain boundaries of the bottom zone of the coating in $\mathrm{Ni2OCr}$ appear from the limited dissolution of $\mathrm{Cr}$ in the aluminides [31,32]. The precipitates composed of refractory elements in the interdiffusion zone of the coating grown in René 125 appear because of their low solubility in the aluminide phases $[2,6]$. 


\section{2.- Dissolution and passivation}

The dissolution of the aluminide coatings has been rarely studied. Most of the works refer to chemical stripping of these coatings on nickel-based superalloys $[\mathbf{7 , 8 , 1 1}]$ and on steels [33]. However, this work is focused on the electrochemical stripping of nickel aluminide coatings. It seems that the mechanisms of dissolution and of passivation in this particular aqueous electrolytic solution (5 wt\% $\mathrm{HNO}_{3}, 2 \mathrm{wt} \%$ $\mathrm{HCl}$ and 0.7 wt\% $\left.\left(\mathrm{NH}_{4}\right)_{6} \mathrm{Mo}_{7} \mathrm{O}_{24}, 4 \mathrm{H}_{2} \mathrm{O}\right)$ and $\left.(\mathrm{pH} \sim 0)\right)$ are ruled by chemical and electrochemical reactions.

In diluted nitric acid media, the reactions occur through equations (1-3) [33]:

$$
\begin{aligned}
& 8 \mathrm{Al}+6 \mathrm{NO}_{3}{ }^{-}+30 \mathrm{H}^{+}(\mathrm{aq}) \rightarrow 8 \mathrm{Al}^{3+}(\mathrm{aq})+3 \mathrm{~N}_{2} \mathrm{O}(\mathrm{aq})+15 \mathrm{H}_{2} \mathrm{O} \\
& 4 \mathrm{Ni}+2 \mathrm{NO}_{3}{ }^{-}+10 \mathrm{H}^{+}(\mathrm{aq}) \rightarrow 4 \mathrm{Ni}^{2+}(\mathrm{aq})+\mathrm{N}_{2} \mathrm{O}(\mathrm{aq})+5 \mathrm{H}_{2} \mathrm{O} \\
& 1.6 \mathrm{NiAl}+2 \mathrm{NO}_{3}{ }^{-}+10 \mathrm{H}^{+}(\mathrm{aq}) \rightarrow 1.6 \mathrm{Ni}^{2+}(\mathrm{aq})+1.6 \mathrm{Al}^{3+}(\mathrm{aq})+\mathrm{N}_{2} \mathrm{O}(\mathrm{aq})+5 \mathrm{H}_{2} \mathrm{O}
\end{aligned}
$$

In addition, the Pourbaix diagrams of $\mathrm{Al}[34]$ and of $\mathrm{Ni}[35]$ clearly indicate that at $\mathrm{pH} 0$ and in the anodic domain (0.5 V/SCE), $\mathrm{Ni}^{2+}$ and $\mathrm{Al}^{3+}$ cationic species are stable. However, $\mathrm{Ni}$ is immune in the cathodic domain (-0.8 V/SCE) but not $\mathrm{Al}$, which remains in the $\mathrm{Al}{ }^{3+}$ form at $\mathrm{pH} 0$. This suggests that $\mathrm{Ni}$ remains stable when the polarization is cathodic while $\mathrm{Al}$ and Ni dissolve upon the anodic polarization. This is confirmed in Fig. 6b, where the bulk NiAl dissolves constantly with time under continuous anodic polarization.

Also, the chloride ions are assumed here to degrade the passive film formed on NiAl upon the cathodic polarization steps and would be thus responsible for the pit initiation observed on the stripped surfaces shown in Figures 4, 5 and 7. Indeed, Marcus and Herbelin showed that chloride ions could enter the passive films of nickel immersed in $0.05 \mathrm{M} \mathrm{H}_{2} \mathrm{SO}_{4}$ with different concentrations of $\mathrm{HCl}$ [36]. At potentials in the active region, the chloride ions entered the outer hydroxide layers and formed a thin hydroxy-chloride layer in which the chloride content increased with the potential. In contrast, the surface concentration of $\mathrm{Cl}^{-}$dropped markedly when the active/passive potential was reached. Yet, chlorides incorporated in the passive film formed in the passive domain. Bennour et al. demonstrated by XPS that the chloride ions promoted the hydroxylation reactions of a thermally grown $\theta-\mathrm{Al}_{2} \mathrm{O}_{3}$ on pure NiAl immersed in $0.5 \mathrm{M} \mathrm{NaCl}$ to result in a Cl-containing Al hydroxides film [12]. The surface of $\mathrm{NiAl}$ became depleted in $\mathrm{Al}$ while $\mathrm{Ni}$ incorporated in the film as a spinel oxide rather than as nickel hydroxide. This reduced further the corrosion resistance. These reports would agree with our XPS and TEM/SADPS results where AIOOH is one of the major constituents of the passive film but we did not find any oxidized nickel. In addition, here, the use of alternated cathodic and anodic polarizations 
appears to avoid the incorporation of chloride ions to the surface layers as they have not been identified in our XPS analyses.

On the other hand, the main electrochemical features of the aluminized and the uncoated pure $\mathrm{Ni}$, model Ni20Cr and René $125 \mathrm{Ni}$-based superalloy gathered in Table 1 clearly show that pure nickel and nickel aluminide are active while the incorporation of alloying elements renders the surfaces passive in the electrolytic medium employed here. In particular, the results are quite comparable between the model $\mathrm{Ni20} \mathrm{Cr}$ and the René $125 \mathrm{Ni}$-based superalloy in both the aluminized and in the uncoated conditions, which suggest that $\mathrm{Cr}$ is majorly responsible for the passivity. This is supported by the findings of Fig. 3, where the decrease of the current density with dissolution time is proportional to the drop of the Al content with coating depth in both the aluminized $\mathrm{Ni}$ and René 125 superalloy but not in the aluminized Ni20Cr. Another proof to support this major passive effect provided by $\mathrm{Cr}$ is the lower current density of the aluminized René 125 than in aluminized Ni20Cr during the first dissolution step (Fig. 2) as the former contains a greater concentration of $\mathrm{Cr}$ (2.9 at\%) than the latter (1.3 at\%) at the surface. Therefore, the intermediate steps of cathodic polarization allow the passivation of the surface to a greater extent in the aluminized Ni20Cr than in the aluminized Ni and René 125 (Figs. 4 and 5).

The differences in dissolution behaviour can be also due to the alloying elements other than $\mathrm{Cr}$. This hypothesis is sustained when comparing the electrochemical reactivity of the aluminide coatings of $\mathrm{Ni20Cr}$ and René 125 superalloy (Figs. 3 and 6). The latter incorporates $\mathrm{Co}>\mathrm{Ti}>\mathrm{Mo} \sim \mathrm{W} \sim \mathrm{Ta}$ in addition to $\mathrm{Cr}$ in the nickel aluminide coating. In uncoated Inconel 718, Incoloy 925, and MP35N superalloys passivated in acetate buffer, Pound et al. found by XPS that the passive films are mostly composed of $\mathrm{Cr}$ oxide into which other elements like $\mathrm{Mo}, \mathrm{Nb}$ and $\mathrm{Cu}$ contribute to foster passivation [37]. In addition, Liu et al. also reported in their XPS studies that the passive layer formed on a nanocrystalline Ni-based superalloy coating immersed in mixtures of $0.05 \mathrm{M} \mathrm{H}_{2} \mathrm{SO}_{4}$ with $\mathrm{NaCl}$ was also composed of $\mathrm{Cr}_{2} \mathrm{O}_{3}$ to which some (unquantified) Ti had incorporated [38]. They also concluded that the lowest nanocrystallinity of the coatings fostered the formation of the passive film, hence impeding the penetration of the chloride ions, which is much in line with our TEM observations. However, Makino et al. discovered that the increasing additions of $\mathrm{Co}(0$ to $40 \% \mathrm{Co}$ ) to $\mathrm{Ni} 12 \mathrm{Cr}$ and to $\mathrm{Ni2OCr}$ facilitated dissolution in mixtures $3 \mathrm{M} \mathrm{NaNO}_{3}$ and in $3 \mathrm{M} \mathrm{NaCl}$ in the active domain [39]. $\mathrm{Co}^{2+}$ did not seem to incorporate to the passive film in the more $\mathrm{Cr}$ concentrated $\mathrm{Ni2OCr}$, i.e. the passivating effect of $\mathrm{Cr}$ was predominant. Although we could not carry out XPS measurements of the aluminized René 125 superalloy, the electrochemical features of Figs. 2 and 6 would confirm the activity provided by (at least) Co since the $\mathrm{Cr}$ content in the 10 first $\mu \mathrm{m}$ of the coatings is greater in the aluminized René 125 (2.9 at\%) than in the aluminized Ni20 Cr (1.3 at\%) (Figs. 1e and 1f). 
However, the main surface products after the anodic and the cathodic polarizations seem to be just composed of $\mathrm{Cr}$ and Al oxy-hydroxides according to the Raman spectra (Fig. 8 and Table 2). This suggests that the species ruling the surface activity and passivity in the aluminide coating are only Al and $\mathrm{Cr}$. This is demonstrated in the XPS analyses of Tables 3 and 4, where the major elements are in the oxidized state after the cathodic polarization while their ground states are generally more abundant after the anodic polarization. Therefore, the XPS measurements of the "non-stripped" areas reflect the composition of the "unbroken" passive films formed after the cathodic polarization steps with much less content of $\mathrm{Ni}$ than in the stripped areas (Table 5). Such films appear to be mostly composed of mixed oxy-hydroxides of $\mathrm{Al}^{3+}$ and of $\mathrm{Cr}^{3+}$. The TEM/SADPs of Fig. 10 and Table 6 clearly show that the outermost surface is composed of $\mathrm{CrOOH}(25 \mathrm{~nm})$ followed by $\mathrm{CrOOH}$ and $\mathrm{AlOOH}(100$ $\mathrm{nm})$ and then by $\mathrm{AlOOH}$ and $\mathrm{CrOOH}(150 \mathrm{~nm})$. The diffraction rings suggest that the films are either amorphous or nanocrystalline but the high resolution image showing the interplanar distances at about $2 \mathrm{~nm}$ (Fig. 10b) confirm the nanocrystallinity. In contrast, no Ni oxy-hydroxide could be identified in the diffraction patterns, which is in line with the low Ni content of these zones (Table 5). In addition, the composition of the films obtained by TEM/EDS was $\mathrm{O}, \mathrm{Cr}, \mathrm{Al}$ and $\mathrm{Ni}$ but no Mo was retrieved. The differences with the XPS results simply arise from the different location of the analyses, which are at about 3-5 nm in the XPS while the TEM/SADPs results are obtained deeper in the film (25, 100 and 150 $\mathrm{nm})$.

The formation of double layers in passive films with external $\mathrm{Cr}$ oxy-hydroxides and internal $\mathrm{Cr}$ oxides has been demonstrated in many different substrates by XPS. For instance, Jabs et al. reported that the surface of $\mathrm{Ni} 21 \mathrm{Cr}$ immersed in $1 \mathrm{M} \mathrm{H}_{2} \mathrm{SO}_{4}$ contained $\mathrm{Cr}$ hydroxides and $\mathrm{Cr}$ oxides [40]. By adding some Fe (Ni21Cr8Fe) and in $0.05 \mathrm{M} \mathrm{H}_{2} \mathrm{SO}_{4}$, Marcus and Grimal also demonstrated the same double layer configuration of the passive film but now the internal layer contained about $4 \%$ of $\mathrm{Fe}_{2} \mathrm{O}_{3}$ in addition to $96 \% \mathrm{Cr}_{2} \mathrm{O}_{3}$ [29]. However, only one layer containing a mixture of $\mathrm{Ni}(\mathrm{OH})_{2}, \mathrm{Cr}(\mathrm{OH})_{3}, \mathrm{Cr}_{2} \mathrm{O}_{3}$ and $\mathrm{FeOOH}$ formed in the active domain due to the selective dissolution of $\mathrm{Cr}$ compared to the other elements in Ni17Cr10Fe. Such selective dissolution also occurs with Al from NiAl in $0.5 \mathrm{M} \mathrm{NaCl}$, which may lead to the incorporation of $\mathrm{Ni}$ to the surface film [12]. Here, it is assumed that upon the anodic polarization, the preferential dissolution of $\mathrm{Al}$ and of $\mathrm{Cr}$ with respect $\mathrm{Ni}$ occurs (Table 5), in particular Al whose redox potential is the lowest and is thus leached off the outermost layer. Therefore, $\mathrm{CrOOH}$ is the major species in the outermost layer according to the most external diffraction pattern of Fig. 10c.

The Mo from the electrolytic solution would moderate dissolution. Indeed, the incorporation of Mo to the surface films has been proven to decrease the dissolution rate of Fe-Cr-Mo alloys [14]. Ph. Marcus even described Mo as a "dissolution moderator" due to its high metal-metal bond energy compared to $\mathrm{Cr}$ as a "passivity promoter", which has a combined high metal--oxygen bond strength and low 
metal-metal bond energy [41]. However, according to Breslin et al., molybdates can react with Al in acidic media according to equations (4) to (6) [42]:

$$
\begin{aligned}
& \mathrm{MoO}_{4}^{2-}+2 \mathrm{H}^{+}+2 \mathrm{H}_{2} \mathrm{O}+2 \mathrm{Al} \rightarrow \mathrm{Mo}+\mathrm{Al}_{2} \mathrm{O}_{3} \cdot 3 \mathrm{H}_{2} \mathrm{O} \\
& \mathrm{MoO}_{4}{ }^{2-}+5 \mathrm{H}^{+}+2 \mathrm{Al} \rightarrow \mathrm{Mo}^{3+}+1 / 2 \mathrm{Al}_{2} \mathrm{O}_{3} \cdot 3 \mathrm{H}_{2} \mathrm{O}+\mathrm{H}_{2} \mathrm{O} \\
& 3 \mathrm{MoO}_{4}{ }^{2-}+6 \mathrm{H}^{+}+2 \mathrm{Al} \rightarrow 3 \mathrm{MoO}_{2}+\mathrm{Al}_{2} \mathrm{O}_{3} \cdot 3 \mathrm{H}_{2} \mathrm{O}
\end{aligned}
$$

Therefore, the alumina would be rather in a hydrated state, which in our case is clearly an oxyhydroxide close to $\delta$-AlOOH and Mo would appear as both the metal (reaction (4)) and the oxidized state (reactions (5) and (6)). Here, the anodic polarization seems thus to oxidize further $\mathrm{Mo}^{+3}$ and $\mathrm{Mo}^{+4}$ $\left(\mathrm{MoO}_{2}\right)$ of reactions (5) and (6) into $\mathrm{Mo}^{+6}$ oxidation state. Indeed, the Pourbaix diagram of Mo shows that the molybdates decompose in acidic media to result in molybdic acids upon the anodic polarization (0.5 V/SCE) at $\mathrm{pH} 0$ and in metal Mo upon the cathodic polarization (-0.8V/SCE) [34]. Subsequently, the rapid change from anodic to cathodic polarization allows the trapping of $\mathrm{Al}, \mathrm{Cr}$ and Mo in the oxidized modes as oxyhydroxides while some reduction also occurs, in particular of $\mathrm{Cr}$.

\section{5.- Conclusions}

The dissolution of aluminide coatings on model (pure Ni, Ni20Cr) and René $125 \mathrm{Ni}$-based superalloy in aqueous solutions of $5 \% \mathrm{HNO}_{3}+2 \% \mathrm{HCl}+0.7 \%\left(\mathrm{NH}_{4}\right)_{6} \mathrm{Mo}_{7} \mathrm{O}_{24}, 4 \mathrm{H}_{2} \mathrm{O}(\mathrm{wt} \%)$ are demonstrated to occur by both chemical and electrochemical reactions. The nitric acid assists in the chemical dissolution of $\mathrm{Al}$ and the molybdate ions may have oxidized Al. As for the chloride ions, they may have contributed to the breakage of the passive films but we do not have sufficient experimental evidence to demonstrate it. Upon anodic polarization, the dissolution occurs by leaching off Al from the outermost layers of the coating. The rapid change to cathodic polarization brings about effective passivation where the layers are mostly composed of $\mathrm{CrOOH}$ and $\mathrm{AlOOH}$ that block dissolution. The elimination of the cathodic steps allows continuous dissolution. 


\section{6.- Acknowledgements}

SAFRAN Aircraft Engines (France) and SR Technics Airfoil Services (Ireland) are gratefully acknowledged for providing some of the coatings and the superalloy substrate. Y. Le Guével is particularly grateful to SAFRAN Aircraft Engines (France) for funding his PhD.

\section{7.- References}

1. R.E. Reed, The Superalloys Fundamentals and Applications, Cambridge University Press, Cambridge, United Kingdom (2006) p. 2.

2. F. Pedraza, C. Tuohy, L. Whelan, A.D. Kennedy, High quality aluminide and thermal barrier coatings deposition for new and service exposed parts by CVD techniques, Mater. Sci. Forum. 461-464 (2004) 305-312.

3. M.J. Pomeroy, Coatings for gas turbine materials and long term stability issues, Mater. Design 26 (2005) 223-231.

4. A. Agüero, V. González; M. Gutiérrez, R. Knödler, R. Muelas, S. Straub, Comparison between field and laboratory steam oxidation testing on aluminide coatings on P92, Mater. Corr. 62 (2011) 561658.

5. F. Rouillard, J-L. Courouau, B. Duprey, S. Mathieu, M. Vilasi, Y. Bouizi, G. Boissonnet, F. Pedraza, I. Proriol-Serre, Evaluation of the compatibility of aluminide coatings in high temperature sodium for Fast Reactor applications, Oxid. Met. 88 (2017) 221-233.

6. B. Bouchaud, J. Balmain, F. Pedraza, Cyclic and isothermal oxidation at $1,100^{\circ} \mathrm{C}$ of a CVD aluminised directionally solidified Ni Superalloy, Oxid. Met. 69 (2008) 193-210.

7. S. Poupard, J-F. Martinez, F. Pedraza, Soft chemical stripping of aluminide coatings and oxide products on Ni superalloys, Surf. Coating Technol. 202 (2008) 3100-3108.

8. Z. Alam, S.B. Sarkar, D.K. Das, Refurbishment of thermally degraded diffusion Pt-aluminide (PtAl) bond coat on a Ni-base superalloy, Surf. Coating Technol. 354 (2018) 101-111.

9. B. Bouchaud, J. Creus C. Rébéré, J. Balmain, F. Pedraza, Controlled stripping of aluminide coatings on nickel superalloys through electrolytic techniques, J. Appl. Electrochem. 38 (2008) 817-825.

10. Y. Le Guével, B. Grégoire, B. Bouchaud, P. Bilhé, A. Pasquet, M. Thiercelin, F. Pedraza, Influence of the oxide scale features on the electrochemical descaling and stripping of aluminide coatings, Surf. Coating Technol. 292 (2016) 1-10.

11. J.D. Ward, L. Zhang, US Patent 2015/000696A1: Method for smut removal during stripping of coating.

12. I. Bennour, V. Maurice, Ph. Marcus, X-ray photoelectron spectroscopy study of the interaction of ultra-thin alumina films on NiAl alloys with NaCl solutions, Surf. Interface Anal. 42 (2010) 581-587. 
13. W. Power, F. Pedraza Diaz, B. Bouchaud, EP Patent 2015/2679705B1: Electrolytic Stripping.

14. Ph. Marcus, I. Olefjord, A round robin on combined electrochemical and AES/ESCA characterization of the passive films on Fe-Cr and Fe-Cr-Mo alloys, Corros. Sci. 28 (1988) 589-602.

15. F. Pedraza, A.D. Kennedy, J. Kopecek, P. Moretto, Investigation of the microstructure of platinummodified aluminide coatings, Surf. Coating Technol. 200 (2006) 4032-4039.

16. Z. Zhou, H. Guo, J. Wang, M. Abbas, S. Gong, Microstructure of oxides in thermal barrier coatings grown under dry/humid atmosphere, Corros. Sci. 53 (2011) 2630-2635.

17. J. Zhang, H.-T. Li, J-H. Guo, F-R. Chin, Raman scattering modification induced by structural change in alumina polymorphs, Chinese Phys. Lett. 32 (2015) 126801-1 - 126801-4.

18. ruff.info (accessed to: 7 October 2018)

19. M. Kemdehoundja, J. F. Dinhut, J. L. Grosseau-Poussard, M. Jeannin, High temperature oxidation of $\mathrm{Ni}_{70} \mathrm{Cr}_{30}$ alloy: Determination of oxidation kinetics and stress evolution in chromia layers by Raman spectroscopy, Mater. Sci. Eng. A435-436 (2006) 666-671.

20. U. Malayoglu, A. Neville, G. Beamson, Characterisation of the passive film on HIPed Stellite 6 alloy using X-ray photoelectron spectroscopy, Mater. Sci. Eng A393 (2005) 91-101.

21. M.C. Biesinger, B.P. Payne, A.P. Grosvenor, L.W.M. Lau, A.R. Gerson, R.St.C. Smart, Resolving surface chemical states in XPS analysis of first row transition metals, oxides and hydroxides: $\mathrm{Cr}$, Mn, Fe, Co and Ni, Appl. Surf. Sci. 257 (2011) 2717-2730.

22. NIST X-Ray Photoelectron Spectroscopy Database Version 2.0, US Dept. of Commerce, Gaithersburg, USA (1997).

23. B. Vincent Crist, The Elements and Native Oxides, John Wiley \& Sons, Chichester, U.K. (2000), p. 505.

24. Ph. Marcus, J. Oudar, I. Olefjord, Studies of the influence of sulphur on the passivation of nickel by Auger electron spectroscopy and electron spectroscopy for chemical analysis, Mater. Sci. Eng. 42 (1980) $191-197$.

25. C. M. Abreu, M. J. Cristóbal, R. Figueroa, G. Peña and M. C. Pérez, An XPS study on the influence of nitrogen implantation on the passive layers developed on different tempers of AA7075 aluminum alloy, Surf. Interface Anal. 2010, 42, 592-596.

26. C.M. Abreu, M.J. Cristóbal, X.R. Nóvoa, G. Peña, M.C. Perez, R.J. Rodríguez, Modifications of the stainless steels passive film induced by cerium implantation, Surf. Coatings Technol. $158-159$ (2002) 582-587.

27. Ph. Marcus, J.M. Grimal, The antagonistic roles of chromium and sulphur in the passivation of NiCr-Fe alloys studied by XPS and radiochemical techniques, Corros. Sci. 31 (1990) 377-382.

28. F. Pedraza, E. Román, M.J. Cristóbal, M.P. Hierro, F.J. Pérez, Effects of yttrium and erbium ion implantation on the AISI 304 stainless steel passive layer, Thin Solid Films 414 (2002) 231-238. 
29. Ph. Marcus, J.M. Grimal, The anodic dissolution and passivation of $\mathrm{Ni}-\mathrm{Cr}-\mathrm{Fe}$ alloys studied by ESCA, Corros. Sci. 33 (1992) 805-814.

30. D.K. Das, V. Singh and S.V. Joshi, Evolution of aluminide coating microstructure on nickel-base cast superalloy CM-247 in a single-step high-activity aluminizing process, Metall. Mater. Trans A29 (1998) 2173-2188.

31. F.J. Pérez, M.P. Hierro, F. Pedraza, C. Gómez, M.C. Carpintero, J.A. Trilleros, Kinetic studies of Cr and Al deposition using CVD-FBR on different metallic substrates, Surf. Coating Technol. 122 (1999) 281-289.

32. W. J. Cheng, C. J. Wang, Effect of chromium on the formation of intermetallic phases in hot-dipped aluminide Cr-Mo steels, Appl. Surf. Sci. 277 (2013) 139-145.

33. C. Boulesteix, B. Grégoire, F. Pedraza, Oxidation performance of repaired aluminide coatings on austenitic steel substrates, Surf. Coating Technol. 326 (2017) 224-237.

34. M. Pourbaix: Atlas of Electrochemical Equilibria in aqueous solutions, NACE, Houston (1993).

35. E. Protopopoff, P. Marcus: Potential vs. pH (Pourbaix) Diagrams. Corrosion: Fundamentals, Testing and Protection, ASM Handbook Vol. 13A, ASM International, Materials Park, Ohio (2003) pp. 1730.

36. Ph. Marcus, J.-M. Herbelin, The entry of chloride ions into passive films on nickel by spectroscopic (ESCA) and nuclear $\left({ }^{36} \mathrm{Cl}\right.$ radiotracer) methods, Corros. Sci. 34 (1993) 1123-1145.

37. B.G. Pound, C. H. Becker, Composition of surface films on nickel base superalloys, J. Electrochem. Soc. 138 (1991) 696-700.

38. L. Liu, Y. Li, F. Wang, Influence of grain size on the corrosion behavior of a Ni-based superalloy nanocrystalline coating in $\mathrm{NaCl}$ acidic solution, Electrochim. Acta 53 (2008) 2453-2462.

39. E. Makino, N. Motoi, T. Sato, Effects of cobalt on high rate dissolution behaviour of nickel-base superalloys in $\mathrm{NaNO}_{3}$ and $\mathrm{NaCl}$ solutions, Precision Eng. 5 (1983) 65-72.

40. T. Jabs, P. Borthen, and H.-H. Strehblow, X-Ray photoelectron spectroscopic examinations of electrochemically formed passive layers on Ni-Cr Alloys, J. Electrochem. Soc. 144 (1997) 12311243.

41. Ph. Marcus, On some fundamental factors in the effect of alloying elements on passivation of alloys, Corros. Sci. 36 (1994) 2155-2158.

42. C.B. Breslin, G. Treacy, W.M. Carroll, Studies on the passivation of aluminium in chromate and molybdate solutions, Corros. Sci. 36 (1994) 1143-1154. 